Review

\title{
The endocanabinnoid system and diabetes - critical analyses of studies conducted with rimonabant
}

\author{
Ada Letícia B Murro ${ }^{1,2}$
}

\begin{abstract}
Address: ${ }^{1}$ Disciplina de Endocrinologia, Departamento de Clínica Médica, Universidade Estadual de Campinas, Campinas, SP, Brazil and ${ }^{2}$ Disciplina de Endocrinologia, Faculdade de Ciências Médicas, R Vital Brazil, 250, Cidade Universitária Zeferino Vaz, Barão Geraldo, CEP: 13083990, Campinas-SP, Brazil

Email: Ada Letícia B Murro - leticiamurro@uol.com.br
\end{abstract}

Published: 16 October 2009

Diabetology \& Metabolic Syndrome 2009, I:18 doi:10.1186/1758-5996-I-18

This article is available from: http://www.dmsjournal.com/content/I/I//8

(C) 2009 Murro; licensee BioMed Central Ltd.

This is an Open Access article distributed under the terms of the Creative Commons Attribution License (http://creativecommons.org/licenses/by/2.0), which permits unrestricted use, distribution, and reproduction in any medium, provided the original work is properly cited.
Received: 28 April 2009

Accepted: 16 October 2009

\begin{abstract}
Rimonabant is the first $\mathrm{CBI}$ receptor inhibitor available in the Brazilian market. This new drug has been approved for the treatment of obese or overweight patients associated with cardiovascular risk factors. In this article it is compared the effects of rimonabant treatment in obese patients with cardiovascular risk factors to usual obesity pharmacological treatment.
\end{abstract}

\section{Background}

Rimonabant is the first CB1 receptor inhibitor available in the Brazilian market. This new drug has been approved for the treatment of obese or overweight patients associated with cardiovascular risk factors. This way, it is important to emphasize that the Rimonabant drug has not been approved for the treatment of patients with isolated cardiovascular risks, but rather for the treatment of excess weight. It is questioned whether the effect of Rimonabant regarding cardiovascular risk factors (lowering blood pressure, promoting lipid profile improvement, and reduction of glycated hemoglobin) is related to weight loss, or whether risk factor improvement is superior to other antiobesity medications or to weight loss based on life style change.

Studies show that Rimonabant-driven weight loss is superior compared to placebo. However, to date, there are no studies which compare Rimonabant to other anti-obesity drugs or intensive life style change, such as the Diabetes Prevention Programme (DPP). The DPP compared the effects of the use of metformin to the change in life style and it was shown that the latter resulted in greater weight loss and cardiovascular risk factor improvement.
Next, the effects of Rimonabant over each cardiovascular risk will be discussed.

\section{Blood Pressure}

Rimonabant has been announced as the drug to result in blood pressure reduction. The study to show the most relevant blood pressure drop was the RIO-Lipids, which evinced a 2.1-mmHg in systolic BP in the Rimonabant group, and a $1.7-\mathrm{mmHg}$ drop upon the subtraction of the placebo effect [1]. Although statistically relevant, the little clinical significance of this value leads to the conclusion that the effect of this drug on blood pressure is null.

\section{Lipids}

Regarding lipids in multivariate analyses, there seems to be a non-weight-dependent percentage of improvement. The use of Rimonabant compared to placebo resulted in a difference of nearly 12\% in HDL-cholesterol increase and a nearly $12 \%$ increase in triglycerides levels. The presentation of the effect of the drug over a certain variable through a percentage value, although useful from the statistical standpoint, might many times overshadow the magnitude of the actual effect possibly expected from the drug, in absolute numbers. Therefore, it is worth observ- 
ing the effect caused by Rimonabant, on average, in absolute numbers over lipids. In the RIO-Lipids study, the increase in HDL-cholesterol was $3.13 \mathrm{mg} / \mathrm{dL}$ greater than the placebo, on average, on the Rimonabant group[1]. The RIO-Diabetes study shows, as a result, an average improvement of $3.9 \mathrm{mg} / \mathrm{dL}$ in men upon the subtraction of the placebo effect[2]. The residual impact of Rimonabant over HDL, i.e., the post-adjustment effect for weight loss, was accountable for $57 \%$ of the improvement. Again, analyzing in absolute numbers, it was found that Rimonabant, regardless of the weight loss, led to an average 2.22 $\mathrm{mg} / \mathrm{dL}$ increase in HDL. Analyzing the group that presented weight loss under $5 \%$ of the initial weight, the Rimonabant group presented a $1.66 \%$ increase in HDL, on average. The issue brought about when assessing the effect of the drug, regardless of the weight, is whether the improvement is clinically significant and if it can be converted into genuine reduction in cardiovascular risk.

Comparing Rimonabant to other drugs which also promote weight loss like sibutramine (an anti-obesity drug, whose effect is similar to Rimonabant, except for its noneffect over the endocanabinnoid system), within a year, it was observed that weight loss was accompanied by a $15 \%$ increase in HDL cholesterol[3]. This improvement is due to weight loss, once this is the only effect of the drug.

Among patients who lost less than $5 \%$ of their weight, the Rimonabant group presented a $5.2 \%$ reduction in triglycerides, on average, compared to placebo. Once again, the question is raised as to the clinical meaning of this reduction.

These data lead us to question if the weight loss induced by Rimonabant brings any additional clinically significant benefit when compared to weight loss by any other antiobesity drug, or even due to changes in life style.

Studies published to date do not demonstrate an improvement in LDL, which is considered the cholesterol fraction to be more closely linked to cardiovascular risk.

\section{Glycemic control}

The two studies available and published with Rimonabant in diabetic patients, Rio-Diabetes and Serenade, showed an improvement in glycated hemoglobin of nearly $0.5 \%$ compared to placebo[4].

Anderson et col. published in 2003 a meta-analysis of various studies which interfered in diabetic patients' weight[5]. It demonstrated that, regarding baseline values, there was an improvement in several parameters such as the reduction of fasting glycemia, cholesterol, LDL, triglycerides and systolic and diastolic blood pressure. The only factor where an improvement was not observed was in HDL, although some studies revealed a worsening of the condition. The conclusion of the meta-analysis was that weight reduction in diabetic patients, regardless of the treatment, improves cardiovascular risk, except HDL, in a comparable magnitude to that observed with Rimonabant. In this meta-analysis, no mentions were made to glycated hemoglobin. In a meta-analysis of studies conducted with sibutramine, considering glycated hemoglobin as a parameter, a substantial variability was observed in the decrease of HbA1c (0 to 1.34\%), with an average reduction of $0.28 \%$. Of the studies included, only three presented statistical significance[6]. Considering these data, it is possible that Rimonabant is more effective in reducing glycated hemoglobin than weight loss alone. However, the change in stratified HbA1c by weight loss was not published, which would lead us to conclude if there is actually an improvement beyond weight loss. Thus, the doubt remains whether the $0.5 \%$ reduction in glycated hemoglobin is weight-dependent or if this reduction goes beyond weight loss.

\section{Inflammatory Markers}

Regarding inflammatory markers, which are currently also considered cardiovascular risk markers, their improvement was also observed in studies with Rimonabant. In the RIO-Lipids study, there was a $29 \%$ reduction in the C reactive protein (CRP), and in the RIO-Diabetes study, the CRP reduction was 26\% [2]. Recently, Copolla et cols. demonstrated that the reduction of BMI from 34.4 to 30.1 on average with a multidisciplinary treatment in the course of one year was followed by a $40 \%$ drop in CRP levels[7], i.e., effective weight loss may improve CRP levels in greater magnitude than with Rimonabant.

Considering adiponectin, the RIO-Lipids study showed an increase in adiponectin to $1.5 \mu \mathrm{g} / \mathrm{ml}$, upon subtraction of the placebo effect. A multivariate analysis demonstrated that $57 \%$ of this effect would be a result of the blockage of the $\mathrm{CB} 1$ receptor rather than weight loss. However, the same study already previously mentioned, which demonstrated the reduction of CRP with weight loss, also evaluated adiponectin, having observed an average increase of $58.8 \%$ in adiponectin[7].

Also, despite the low levels of adiponectin having been related to greater cardiovascular risk, it is worth pointing out that the clinical significance of adiponectin increase is yet undefined. Glitazones, sensitizers of the insulin action which increase adiponectin levels more remarkably than Rimonabant [8], still have not proven to reduce cardiovascular risk.

It is known that other drugs, such as glimepiride, are capable of increasing adiponectin levels up to $50 \%$, despite their lack of effect over body weight[9]. 
Another factor that results in an increase in adiponectin levels is physical exercise, possibly due to an improvement in insulin resistance. In a study where physical exercise was performed through a period of 10 weeks, without leading to weight loss, the average adiponectin level increased over $100 \%[10]$. These data suggest that the observed adiponectin increase with Rimonabant is inferior to that obtained with the above described interventions. Also, once again, the significance of this increase is still undefined.

Another factor worth emphasizing is the way this datum is presented, both in publications and in product promotional materials - at times, it conveys the impression that the magnitude of the event is greater than what is verified in absolute numbers. As an example, the information that $45 \%$ of the improvement in HDL observed in studies with Rimonabant is not explained by weight loss sounds more important than the information that a 3.6\% increase in HDL induced by Rimonabant is not explained by weight loss, specially considering that this increase would be nearly $1.4 \mathrm{mg} / \mathrm{dL}$ in absolute numbers. Also, and once again, the clinical significance of this change is still questioned.

\section{Atheromatous plaque}

The Stradivarius study recently published, analyzed the effect of the use of Rimonabant over the atheromatous plaque, which was being expected as it was the first study to propose to assess if the use of Rimonabant did actually result in the reduction of the atheromatous plaque evaluated by the coronary ultrasound. In this study, according to the primary endpoint, the percentage volume of the atheromatous plaque did not show an improvement compared to placebo. The only significant improvement among Rimonabant users compared to placebo was observed in the subgroup that was not given statins[11]. Considering that most patients to whom Rimonabant is indicated have high cardiovascular risk, these patients must already be using statins, i.e., this subgroup probably corresponds to a small share of the high cardiovascular risk population.

\section{Safety}

A meta-analysis of the safety and efficacy of Rimonabant was recently published, evaluating the data of four studies with Rimonabant, at a total of 4105 patients. The average weight loss was $4.7 \mathrm{~kg}$, having subtracted the placebo effect; patients using Rimonabant had a chance five times greater of presenting weight loss over $2 \%$. The main adverse effects reported, which in reality is the greatest concern of us physicians, were of psychiatric nature[12]. One of endocannabinnoid agonists is known as anandamide. The term ananda, from Sanskrit, means "internal bliss". The term might reveal well some of the physiolog- ical functions of the endocannabinoid system in the central nervous system. Di Marzo summarized some of these functions as "feeling less pain, controlling one's movements, relaxing, eating, forgetting, sleeping and protecting"[13]. This way, it is expected that the intervention in this system be followed by other effects rather than the reduction in food intake.

Objectively, the relative risk of a patient using Rimonabant developing an adverse event is 1.4 , and the NNH (number needed to harm), i.e., the number of patients treated so that one patient will present any adverse event, is 25 . For a serious adverse event, the NNH is 59 . The relative risk of a patient taking Rimonabant to discontinue the medication due to depression is 2.5. For every 49 patients treated, one discontinued the treatment due to depression, and for every 166 patients treated, one had to stop due to anxiety[12].

\section{Final considerations}

It is undebatable that weight loss induced by Rimonabant is clinically significant and that it results in a metabolic profile. However, weight loss cannot be mistaken for other more clinically relevant endpoints, and the greatest concern and expectation of the medical community revolves around cardiovascular risk, whose reduction still has not been demonstrated. The termination of other ongoing studies, the main being the CRESCENDO study, will show if the drug genuinely brings effect to cardiovascular mortality, which in the end is what matters the most to us, and clarify if this effect adds to that of drugs which present a well established cardiovascular benefit, such as statins.

\section{Competing interests}

The author declares that she has no competing interests.

\section{References}

I. Després JP, Golay A, Sjöström : Effects of Rimonabant on metabolic risk factors in overweight patients with dyslipidemia. $\mathrm{N}$ Engl J Med 2005, 353:2 I21-34.

2. Scheen AJ, Finer N, Hollander P, Jensen MD, Van Gaal LF: Efficacy and tolerability of Rimonabant in overweight or obese patients with type 2 diabetes: a randomised controlled study. The Lancet 2006, 368:1660-72.

3. James WP, Astrup A, Finer N, Hilsted J, Kopelman P, Rössner S, Saris WH, Van Gaal LF: Effect of sibutramine on weight maintenande after weight loss: a randomized trial. The Lancet 2000 , 356:2119-25

4. Rosenstock J, Hollander P, Chevalier S, Iranmanesh A: SERENADE: the study evaluating Rimonabant efficacy in drug-naïve patients: effects of monotherapy with Rimonabant, the first selective CB I receptor antagonist, on glycemic control body weight and lipid profile in drug-naïve type 2 diabetes. Diabetes Care 2008, 3 I (II):2196-76.

5. Anderson JW, Kendall CW, Jenkins DJ: Importance of weight management in type 2 diabetes: review with meta-analysis of clinical studies. J Am Coll Nutr 2003, 22(5):33I-339.

6. Vettor R, Serra R, Fabris R, Pagano C, Federspil G: Effect of sibutramine on weight management and metabolic control in type 2 diabetes: a meta-analysis of clinical studies. Diabetes Care 2005, 28(4):942-949. 
7. Coppola A, Marfella R, Coppola L, Tagliamonte E, Fontana D, Liguori E, Cirillo T, Cafiero M, Natale S, Astarita C: Effect of weight loss on coronary circulation and adiponectin levels in obese women. Int J Cardiol 2009, I34:414-4I6.

8. Oz O, Tuncel E, Eryilmaz S, Fazlioglu M, Gul CB, Ersoy C, Ocak N, Dirican M, Cangur S, Baran I, Imamoglu S: Arterial elasticity and plasma levels of adiponectin and leptin in type 2 diabetic patients treated with thiazolidinediones. Endocrine 2008, 33(I): $101-105$.

9. Tsunekawa $T$, Hayashi T, Suzuki $Y$, Matsui-Hirai $H$, Kano H, Fukatsu A, Nomura N, Miyazaki A, Iguchi A: Plasma adiponectin plays an important role in improving insulin resistance with glimepiride in elderly type 2 diabetic subjects. Diabetes Care 2003, 26(2):285-289.

10. Kriketos AD, Gan SK, Poynten AM, Furlen SM, Chisholm DJ, Campbell LV: Exercise increases adiponectin levels and insulin sensitivity in humans. Diabetes Care 2004, 27(2):629-630.

II. Nissen SE, Nicholls SJ, Wolski K, Rodés-Cabau J, Cannon CP, Deanfield JE, Desprès JP, Kastelein JJ, Steinhubl SR, Kapadia S, Yasin M, Ruzyllo W, Gaudin C, Job B, Hu B, Bhatt DL, Lincoff AM, Tuzcu EM: Effect of Rimonabant on progression of atherosclerosis in patients with abdominal obesity and coronary artery disease: the STRADIVARIUS randomized controlled trial. JAMA 2008, 299( I3): 1547-60.

12. Christensen R, Kristensen PK, Bartels EM, Bliddal H, Astrup A: Efficacy and safety of the weight-loss drug Rimonabant: a metaanalysis of randomized trials. Lancet 2007, 370:1706-13.

13. Di Marzo V, Melck D, Bisogno T, De Petrocellis L: Endocannabinoids: endogenous cannabinoid receptor ligands with neuromodulatory action. Trends Neurosci 1998, 2 I(1 2):52 I-528.

Publish with Bio Med Central and every scientist can read your work free of charge

"BioMed Central will be the most significant development for disseminating the results of biomedical research in our lifetime. "

Sir Paul Nurse, Cancer Research UK

Your research papers will be:

- available free of charge to the entire biomedical community

- peer reviewed and published immediately upon acceptance

- cited in PubMed and archived on PubMed Central

- yours - you keep the copyright

Submit your manuscript here:

http://www.biomedcentral.com/info/publishing_adv.asp
BioMedcentral 